\title{
BK Virus Viral Load Measurement
}

National Cancer Institute

\section{Source}

National Cancer Institute. BK Virus Viral Load Measurement. NCI Thesaurus. Code C98710.

The determination of the amount of BK virus viral load present in a sample. 